\title{
Cloacael Carriage and Multidrug Resistance Escherichia coli 0157:H7 from Poultry Farms, Eastern Ethiopia
}

\author{
Mude Shecho, ${ }^{1}$ Naod Thomas, ${ }^{1}$ Jelalu Kemal, ${ }^{2}$ and Yimer Muktar ${ }^{2}$ \\ ${ }^{1}$ School of Veterinary Medicine, Wolaita Sodo University, Wolaita Sodo, Ethiopia \\ ${ }^{2}$ College of Veterinary Medicine, Haramaya University, P.O. Box 138, Dire Dawa, Ethiopia \\ Correspondence should be addressed to Jelalu Kemal; jelaluk@gmail.com
}

Received 1 December 2016; Revised 2 February 2017; Accepted 5 February 2017; Published 27 February 2017

Academic Editor: Antonio Ortega-Pacheco

Copyright (C) 2017 Mude Shecho et al. This is an open access article distributed under the Creative Commons Attribution License, which permits unrestricted use, distribution, and reproduction in any medium, provided the original work is properly cited.

\begin{abstract}
A cross-sectional study was carried out to determine antimicrobial drug resistance patterns of $E$. coli O157:H7 isolates and estimate the level of the pathogen. A total of 194 cloacae swab samples were collected randomly in two poultry farms. Standard cultural, biochemical, and serological (latex agglutination) methods were used to isolate E. coli O157:H7. The isolates were subjected to antimicrobial susceptibility testing using disc diffusion method. Out of 194 cloacae samples examined, $13.4 \%(n=26)$ were found to be positive for E. coli O157:H7. The finding indicated differences in E. coli O157:H7 infection among the different risk factors. Chicken from Adele Poultry Farm showed higher E. coli O157:H7 infection (OR = 3.89) than Haramaya University poultry farm and young birds had more infection $(\mathrm{OR}=4.62)$ than adult birds. Of the total 14 antimicrobials included in the panel of study, the susceptibility results were varied with $96.15 \%$ and $0 \%$ E. coli O157:H7 isolates expressing resistance to erythromycin, clindamycin, spectinomycin, and ciprofloxacin, respectively. Multidrug resistance to more than two antimicrobial agents was detected in 24 (92.30\%) of the isolates. The study showed high presence of antimicrobial resistant isolates of E. coli O157:H7. Further study is required to better understand the ecology and evolution of bacterial resistance to antimicrobial agents.
\end{abstract}

\section{Introduction}

Poultry is a major fast growing source of food in the world today [1]. However, it is one of the commodities most commonly associated with food-borne disease outbreaks. Pathogens can be transmitted to humans directly through contact with poultry litter or indirectly through contaminated poultry products [2]. The avian intestines have been considered as a reservoir of potential $E$. coli with zoonotic potential that could be transferred directly from birds to humans.

E. coli is a commensal bacterium in humans and animals and has a wide range of hosts. It is commonly present in the environment and considered an indicator of fecal contamination in food and water. It can acquire, maintain, and transmit resistance genes from other organisms in the environment. $E$. coli serotype O157:H7 is an enterohaemorrhagic strain, which was initially recognized in the United States of America, as a cause of food-borne illness, and has now emerged as an important enteric pathogen of considerable public health significance [3].
In animal production antimicrobials are widely used as growth promoter and in treatment of infectious diseases. The use of antimicrobials in poultry production industries for promotion of growth largely contributes to the high resistance to antimicrobial agents in normal flora of poultry and pathogenic microorganism [4]. The practice of using antimicrobials in feed may modify the intestinal flora by creating a selective pressure in favor of resistant bacteria populations (such as resistant $E$. coli) that could find their way into the environment and food chain [5]. Due to its ubiquity in humans and animals and its role as a pathogenic and commensal organism, E. coli has become one of the microorganisms that are commonly resistant to antimicrobials [6]. With the constant use of antimicrobials over a period of time, bacteria resist not only single but also multiple antimicrobials making some diseases troublesome to treat [7].

In recent years, antimicrobial resistance especially multidrug resistance has become very common in clinical isolates, including E. coli isolates of animal origin [8]. Antimicrobial resistance among $E$. coli in food animals such as 


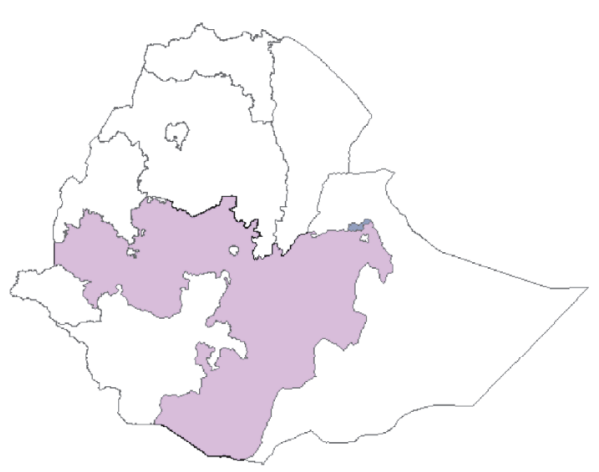

Oromia Region

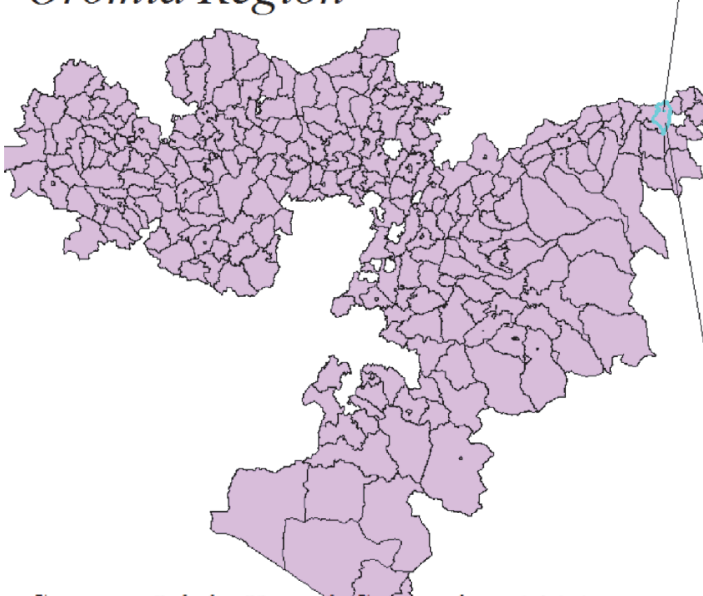

Source: Jelalu Kemal-September, 2016 $41^{\circ} 52^{\prime} 30^{\prime \prime} \mathrm{E} \quad 41^{\circ} 57^{\prime} 0^{\prime \prime} \mathrm{E} \quad 42^{\circ} 1^{\prime} 0^{\prime \prime} \mathrm{E} \quad 42^{\circ} 5^{\prime} 0^{\prime \prime} \mathrm{E} \quad 42^{\circ} 9^{\prime} 30^{\prime \prime} \mathrm{E}$

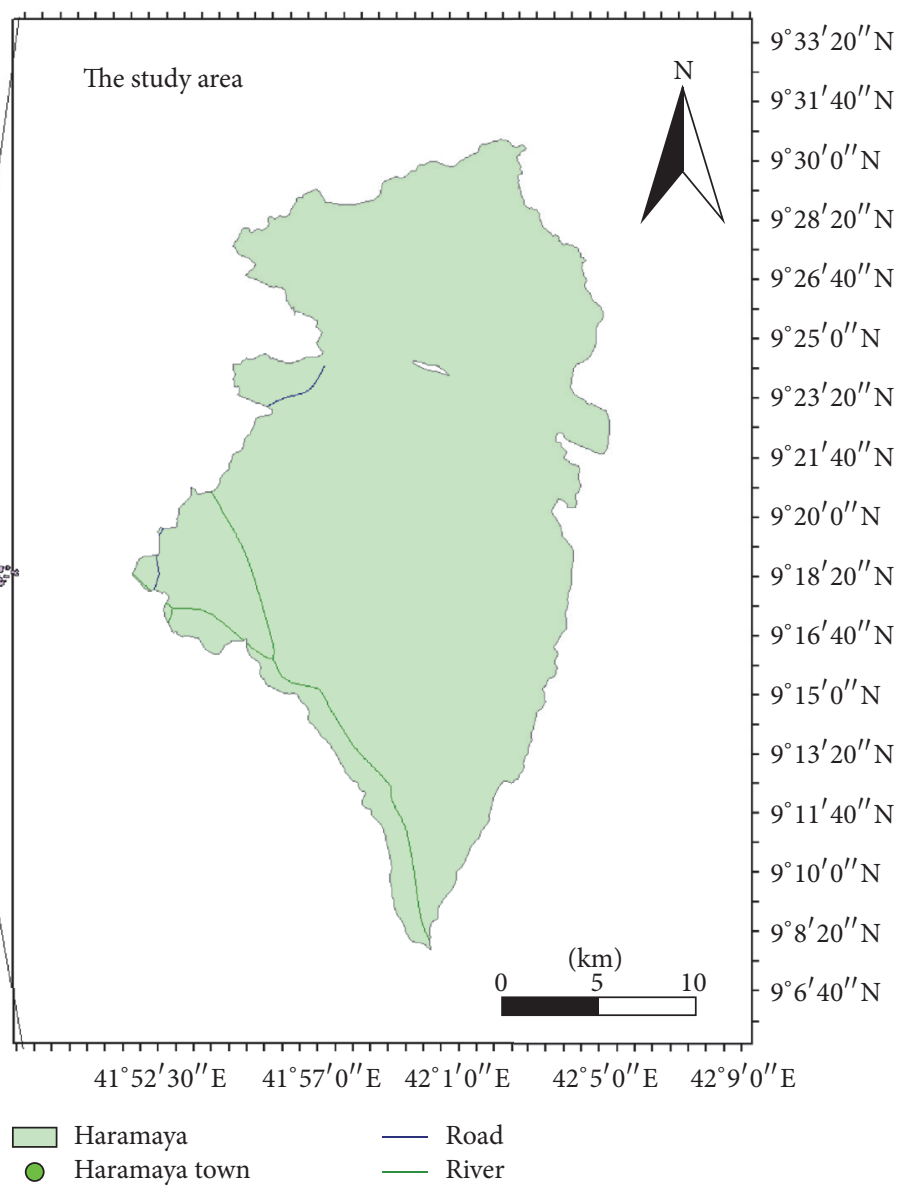

Figure 1: Map showing the study area.

chicken is of increasing concern due to the potential for transfer of these resistant pathogens to the human population [9]. Antimicrobial resistance is a global problem, and emerging antimicrobial resistance has become a public health fact worldwide [10]. The use of antimicrobials in food animals, as well as their role in promoting resistance in food-borne bacteria, is an important public health issue. To measure the baseline resistance rates and the impact of different targeted interventions, an ongoing monitoring system is necessary [6]. Even though there have been few studies about the level and antimicrobial resistance pattern of E. coli O157:H7 in poultry in Ethiopia, information is lacking. Thus, objectives of the study were to determine the antimicrobial resistance patterns of E. coli O157:H7 isolates and estimate the level of the pathogen in apparently healthy birds.

\section{Materials and Methods}

2.1. Study Site Description and Study Population. The study was conducted at Haramaya district Adele Poultry Farm and poultry farm in Haramaya University. Haramaya district is located in eastern Hararge Zone of Oromia Regional State, along the high way from Addis Ababa to Harar $508 \mathrm{~km}$ from Addis Ababa and $19 \mathrm{~km}$ ahead to reach Harar at an altitude of 1980 meters above sea level (m.a.s.l.), $9^{\circ} 26^{\prime} \mathrm{N}$ latitude and $42^{\circ} 3^{\prime} \mathrm{E}$ longitude (Figure 1). The mean annual rainfall is $780 \mathrm{~mm}$. The mean annual minimum and maximum temperatures are 8.5 and $24.4^{\circ} \mathrm{C}$, respectively. Haramaya University poultry farm is located at $42^{\circ} 3^{\prime} \mathrm{E}$ longitude, $9^{\circ} 26^{\prime} \mathrm{N}$ latitude, and an elevation of 1980 m.a.s.l. and $513 \mathrm{~km}$ away from Addis Ababa. The annual mean rain fall of the area amounts to $780 \mathrm{~mm}$ and the average minimum and maximum temperature are $8^{\circ} \mathrm{C}$ and $24^{\circ} \mathrm{C}$, respectively. The total poultry population of the country is estimated to be 56.87 million and it comprises $95.86 \%$ indigenous breeds, $2.79 \%$ crossbreeds, and $1.35 \%$ exotic breeds [12].

This study was conducted on exotic breed chicken under intensive management system. The target population was apparently healthy exotic breed of white leg horn and Feyumi (Egyptian breed) breed chickens. Both farms comprise the aforementioned breeds. Most of these breeds have been from Debre Zeit farms and the fertilized egg was imported from Egypt, Holland, and other countries. Poultry were selected according to their age groups and breeds. The age was conveniently subdivided into young growers up to six months of age and adult chicken. The main purpose of these poultry farms is to supply egg, live chicken for meat, and 3month-old chick to the surrounding farmers and backyard 
and private producers. Furthermore, Haramaya University satisfies its egg demand for its cafeteria of all campuses and the community residing within the university from own farm production. The farms use formulated feed either buying from Debre Zeit or formulating feed on their farm by mixing with local available cereals, pulses, university cafeteria and staff lounge leftovers, and carcass from abattoirs in order to reduce the cost of input.

2.2. Study Design. A cross-sectional purposive type of study was conducted from October 2015 to May 2016 aimed to isolate, identify, and determine the antimicrobial susceptibility profiles E. coli O157:H7 in the area. A total of 194 samples of cloacae swabs were collected randomly from healthy chickens from two poultry farms located in Haramaya University $(n=$ $106)$ and Haramaya district Adele Poultry Farm $(n=88)$, eastern Ethiopia. During the study hypothesized risk factors such as the age, breed, and farm location of the birds were taken into account and recorded.

2.3. Sample Collection. All samples were taken using sterile swabs which were moistened with sterile buffered peptone water (Oxoid Ltd., Cambridge, UK), placed in sterile vial tubes containing $8 \mathrm{~mL}$ buffered peptone water which is used to avoid drying out of the swabs. Samples were kept in ice box containing ice pack for transporting to Haramaya University, College of Veterinary Medicine, Microbiology Laboratory, immediately for further analysis.

2.4. Isolation and Identification of E. coli O157:H7. Isolation and identification of $E$. coli O157:H7 were performed by standard bacteriological methods. The samples were incubated at $37^{\circ} \mathrm{C}$ for $24 \mathrm{hrs}$ on the same day upon arrival at the laboratory on MacConkey agar (Oxoid Ltd., Cambridge, UK) which is selective and differential medium for E. coli [13]. A pink colony was picked and subcultured on Eosin Methylene Blue (EMB) agar (Oxoid Ltd., Cambridge, UK) to obtain pure colony. Colonies with metallic green sheen on EMB (characteristic of E. coli) were later characterized microscopically using Gram's stain according to the method described by Merchant and Packer [14]. After isolation of the organism on the selective media, differential screening media, triple sugar iron (TSI) agar (Difco, MI, USA) was used for further characterization. Yellow slant, yellow butt, presence of gas bubbles, and absence of black precipitate in the butt was observed which indicates E. coli [15]. Then the isolates were subjected to different biochemical tests according to Quinn et al. [16] such as sugar fermentation test and indole production test, methyl-red, Voges-Proskauer, and citrate utilization (IMViC) test. Then the bacterium that was confirmed as E. coli was subcultured onto Sorbitol MacConkey agar (Oxoid Ltd., Cambridge, UK) from nutrient agar and colorless colonies (nonsorbitol fermenter) were again subcultured onto nutrient agar and latex $E$. coli O157:H7 agglutination test was performed to determine strains using polyvalent antisera (DENKA SEIKEN Co. Ltd., Tokyo, Japan).

2.5. Antimicrobial Susceptibility Testing for E. coli O157:H7 Isolates. The antimicrobial susceptibility testing E. coli O157:H7 isolates was conducted using disc diffusion method (KirbyBauer method) on Mueller-Hinton agar (Oxoid Ltd., Cambridge, UK) according to the guidelines of the Clinical and Laboratory Standards Institute [11]. All E. coli O157:H7 isolates were evaluated for antimicrobial susceptibility to 14 antimicrobial agents. A McFarland 0.5 (the turbidity of the test broth was adjusted with saline until the turbidity of the test suspension equated that of the standard) standardized suspension of the bacteria in tryptone soya broth (Oxoid Ltd., Cambridge, UK) was prepared. A bacterial suspension incubated for 6-8 hours was swabbed over the entire surface of Mueller-Hinton agar (Oxoid Ltd., Cambridge, UK) with a sterile cotton swab. The inoculated pates were allowed to stand for 3-5 minutes to observe any excess moisture from the medium before the antimicrobial discs were applied. A ring of discs containing single concentrations of each antimicrobial agent was then placed onto the inoculated surface using disc dispenser, gently pressed with the point of the forceps for ensuring complete contact with the agar surface, and then inverted. After $16-18$ hours of incubation at $35^{\circ} \mathrm{C} \pm 2^{\circ} \mathrm{C}$, aerobically, clear zones produced by antimicrobial inhibition of bacterial growth were measured in $\mathrm{mm}$ using a measuring caliper. For the susceptibility testing, the following 14 antimicrobial drugs and concentrations were used: ampicillin $(10 \mu \mathrm{g})$, amoxicillin $(20 \mu \mathrm{g})$, cefoxitin $(30 \mu \mathrm{g})$, chloramphenicol $(30 \mu \mathrm{g})$, ciprofloxacin $(5 \mu \mathrm{g})$, clindamycin $(30 \mu \mathrm{g})$, erythromycin $(15 \mu \mathrm{g})$, gentamycin $(10 \mu \mathrm{g})$, kanamycin $(30 \mu \mathrm{g})$, nalidixic acid $(30 \mu \mathrm{g})$, spectinomycin $(30 \mu \mathrm{g})$, streptomycin $(10 \mu \mathrm{g})$, tetracycline $(30 \mu \mathrm{g})$, and trimethoprim $(5 \mu \mathrm{g})$ (Oxoid Ltd., Cambridge, UK). The antimicrobials used were selected from the currently available and commonly used chemotherapeutic agents for the treatment of $E$. coli infection in humans and animals. E. coli ATCC25922 and E. coli ATCC35218 were used as quality control during the test. Finally, the findings of antimicrobial resistance testing were recorded as susceptible, intermediate, and resistant according to Clinical and Laboratory Standards Institute break points [11] (Table 1).

2.6. Data Analysis. All the data were coded and entered into Microsoft Excel ${ }^{\circledR}$ 2007. The data were then exported to SPSS windows version 20.0 (SPSS) (IBM, Armonk, USA) for appropriate statistical analysis. The occurrence of the pathogen was determined by using descriptive statistics. Chi square $\left(\chi^{2}\right)$ and odds ratio were used to measure the association between the different risk factors and occurrence of $E$. coli O157:H7 in chicken cloacae. Effects were reported as statistically significant if $P$ value is less than $5 \%(P<0.05)$.

\section{Results}

3.1. Level of E. coli O157:H7 from Cloacal Fecal Sample. Based on colonial morphology and biochemical and latex agglutination tests, E. coli O157:H7 were isolated from cloacal swab sample of chickens (Table 2). Out of the 194 cloacae samples examined, 26 (13.4\%) were found positive for $E$. coli O157:H7. The results indicated different level of $E$. coli O157:H7 among the different selected risk factors (source, age, and breed) of examined poultry; Haramaya University 
TABLE 1: Zone diameter interpretive standard chart for Enterobacteriaceae [11].

\begin{tabular}{|c|c|c|c|c|}
\hline \multirow{2}{*}{ Antimicrobial agents and symbols } & \multirow{2}{*}{ Disc potency $(\mu \mathrm{g})$} & \multicolumn{3}{|c|}{ Zone diameter, nearest whole $\mathrm{mm}$} \\
\hline & & Resistance & Intermediate & Susceptible \\
\hline Amoxicillin (AML) & 20 & $\leq 13$ & $14-16$ & $\geq 17$ \\
\hline Ampicillin (AMP) & 10 & $\leq 13$ & $14-16$ & $\geq 17$ \\
\hline Cefoxitin (FOX) & 30 & $\leq 14$ & $15-17$ & $\geq 18$ \\
\hline Chloramphenicol (C) & 30 & $\leq 12$ & $13-17$ & $\geq 18$ \\
\hline Ciprofloxacin (CIP) & 5 & $\leq 14$ & $15-17$ & $\geq 21$ \\
\hline Clindamycin (CLI) & 30 & $\leq 16$ & - & $\geq 17$ \\
\hline Erythromycin (E) & 15 & $\leq 13$ & $14-22$ & $\geq 18$ \\
\hline Gentamycin $(\mathrm{CN})$ & 10 & $\leq 12$ & $13-14$ & $\geq 15$ \\
\hline Kanamycin $(\mathrm{K})$ & 30 & $\leq 13$ & $14-17$ & $\geq 18$ \\
\hline Nalidixic acid (NAL) & 30 & $\leq 17$ & - & $\geq 18$ \\
\hline Spectinomycin (SPT) & 30 & $\leq 11$ & $12-14$ & $\geq 15$ \\
\hline Streptomycin (S) & 10 & $\leq 11$ & $12-14$ & $\geq 15$ \\
\hline Tetracycline (TE) & 30 & $\leq 11$ & $12-14$ & $\geq 15$ \\
\hline Trimethoprim (TRI) & 5 & $\leq 13$ & $14-17$ & $\geq 17$ \\
\hline
\end{tabular}

TABLE 2: Level of E. coli O157:H7 isolates with different hypothesized risk factors from Haramaya University and Adele Poultry Farms.

\begin{tabular}{|c|c|c|c|c|c|c|}
\hline Risk factors & Risk categories & Number examined & Number positive & Proportion (\%) & OR (95\% CI) & $P$ value \\
\hline \multirow{2}{*}{ Source } & HUPF $^{a}$ & 106 & 7 & 6.6 & 1 & \\
\hline & $\mathrm{APF}^{\mathrm{b}}$ & 88 & 19 & 21.6 & $3.89(1.5-11.5)$ & 0.002 \\
\hline \multirow{2}{*}{ Age } & Adult & 93 & 5 & 7.5 & 1 & \\
\hline & Young & 101 & 21 & 18.8 & $4.62(1.6-16.3)$ & 0.021 \\
\hline \multirow{2}{*}{ Breed } & Feyumi & 85 & 7 & 10.6 & 1 & \\
\hline & White Leghorn & 109 & 19 & 15.6 & $2.35(0.9-6.9)$ & 0.310 \\
\hline Total & & 194 & 26 & 13.4 & & \\
\hline
\end{tabular}

${ }^{\mathrm{a}}$ Haramaya University Poultry Farm.

${ }^{\mathrm{b}}$ Adele Poultry Farm.

poultry farm $(7 ; 6.6 \%)$, Adele Poultry Farm (19; 21.6\%), young $(21 ; 18.8 \%)$, adult chicken $(5 ; 7.5 \%)$, White Leghorn (19; 15.6\%), and Feyumi $(7 ; 10.6 \%)$ showed level of E. coli O157:H7, respectively. There was a significant difference in $E$. coli O157:H7 among the farms and age groups $(P<0.05)$. Chicken from Adele Poultry Farm showed E. coli O157:H7 infection four times higher than Haramaya University poultry farm and young birds had more infection than adult birds. However there was an equal chance of E. coli O157:H7 infection among different breeds of chicken.

A total of 26 isolates of E. coli O157:H7 were analyzed, 7 from Haramaya University poultry farm and 19 from Adele Poultry Farm for antimicrobial resistance test. The percentage of isolates susceptible, intermediate, and resistant to each antimicrobial agent is outlined in Table 3. Of the total 14 antimicrobials included in the panel of study, the susceptibility results were varied with $96.15 \%$ and $0 \%$ E. coli O157:H7 isolates expressing resistance to erythromycin, clindamycin, spectinomycin, and ciprofloxacin, respectively. The isolates expressed resistance to ampicillin and amoxicillin at frequencies of $92.30 \%$ and $34.61 \%$, respectively. Cefoxitin and tetracycline resistance occurred at a frequency of $84.61 \%$ and $76.92 \%$, respectively. Relatively similar resistance was observed among kanamycin (15.38), nalidixic acid (23.07), and streptomycin (34.61) while lower resistance was recorded between chloramphenicol (3.84) and gentamycin (7.69). Ciprofloxacin, chloramphenicol, trimethoprim, gentamicin, and streptomycin were the most sensitive antibiotics in the study. Intermediate resistance/susceptibility to various antibiotics were observed for 0-46.15\% E. coli O175:H7 strains.

The level of multiple resistance patterns in E. coli O157:H7 isolates is given in Table 4. Single and multiple resistance to most of the antimicrobials tested were observed. Multidrug resistance was recorded in case of 2-9 antimicrobials for the tested strains. Multidrug resistance to more than two antimicrobial agents was detected in 24 (92.30\%) of the isolates. One isolate was resistant to up to nine antimicrobials tested. The resistance pattern most frequently observed in the isolates was resistance to erythromycin in combination with clindamycin, ampicillin, and cefoxitin 3 (12.5\%). The next most frequent resistance isolates were resistance to erythromycin, cefoxitin, clindamycin, ampicillin, amoxicillin, tetracycline, and kanamycin 2 (8.33\%). Multidrug resistance was defined as resistance exhibited to two or more antimicrobials.

Among the E. coli O157:H7 isolates, 37.5\%, 33.33\%, and $4.16 \%$ expressed resistance to two, four, and nine antimicrobials, respectively (Table 4; Figure 2), and resistance to three and eight antimicrobials occurred at a frequency of 
TABLE 3: Antimicrobial resistance profiles of isolated E. coli O157:H7 from Haramaya University and Adele Poultry Farms.

\begin{tabular}{|c|c|c|c|c|c|}
\hline Antimicrobial agents & Disc potency $(\mu \mathrm{g})$ & Number of isolates & Susceptible $N(\%)$ & Intermediate $N(\%)$ & Resistant $N(\%)$ \\
\hline Amoxicillin & 20 & 26 & $7(26.92)$ & $10(38.46)$ & $9(34.61)$ \\
\hline Ampicillin & 10 & 26 & $0(0.0)$ & $2(7.69)$ & $24(92.30)$ \\
\hline Cefoxitin & 30 & 26 & $2(7.69)$ & $2(7.69)$ & $22(84.61)$ \\
\hline Chloramphenicol & 30 & 26 & $25(96.15)$ & $0(0.0)$ & $1(3.84)$ \\
\hline Ciprofloxacin & 5 & 26 & $27(100)$ & $0(0.0)$ & $0(0.0)$ \\
\hline Clindamycin & 30 & 26 & $0(0.0)$ & $1(3.84)$ & $25(96.15)$ \\
\hline Erythromycin & 15 & 26 & $1(3.84)$ & $0(0.0)$ & $25(96.15)$ \\
\hline Gentamycin & 10 & 26 & $23(88.46)$ & $1(3.84)$ & $2(7.69)$ \\
\hline Kanamycin & 30 & 26 & $10(38.46)$ & $12(46.15)$ & $4(15.38)$ \\
\hline Nalidixic acid & 30 & 26 & $16(61.53)$ & $3(11.53)$ & $6(23.07)$ \\
\hline Spectinomycin & 30 & 26 & $18(69.23)$ & $8(30.76)$ & $0(0.0)$ \\
\hline Streptomycin & 10 & 26 & $17(65.38)$ & $0(0.0)$ & $9(34.61)$ \\
\hline Tetracycline & 30 & 26 & $2(7.69)$ & $4(15.38)$ & $20(76.92)$ \\
\hline Trimethoprim & 5 & 26 & $24(92.30)$ & $0(0.0)$ & $2(7.69)$ \\
\hline
\end{tabular}

TABle 4: Resistance patterns of E. coli O157:H7 isolates form Haramaya University and Adele Poultry Farms against 14 antimicrobial agents.

\begin{tabular}{lcc}
\hline \multirow{2}{*}{ Antimicrobials } & \multicolumn{2}{c}{ E. coli O157:H7 } \\
\hline E, K & 1 & 4.16 \\
E, TE & 2 & 8.33 \\
E, C & 1 & 4.16 \\
E, CLI & 1 & 4.16 \\
E, SPT & 1 & 4.16 \\
E, AMP & 2 & 8.33 \\
E, FOX & 1 & 4.16 \\
E, CLI, TE & 1 & 4.16 \\
E, K, TE & 1 & 4.16 \\
CN, E, TE & 1 & 4.16 \\
E, C, CLI, AMP & 3 & 12.5 \\
E, FOX, C, AML & 1 & 4.16 \\
E, CLI, C, AMP & 1 & 4.16 \\
E, S, C, AML & 1 & 4.16 \\
E, AMP, TE, AML & 1 & 4.16 \\
CN, E, S, AMP & 1 & 4.16 \\
E, CLI, K, AMP, FOX, C, TE, AML & 2 & 8.33 \\
E, CLI, K, AMP, C, TE, TRI, AML & 1 & 4.16 \\
E, S, K, NAL, CLI, C, TE, TRI, AML & 1 & 4.16 \\
\hline Total & 24 & 92.30 \\
\hline
\end{tabular}

E: erythromycin, S: streptomycin, $\mathrm{Nal}=$ nalidixic acid, K: kanamycin, AMP: ampicillin, TE: tetracycline, RIT: trimethoprim, AML: amoxicillin, CIP: ciprofloxacin, CN: gentamycin, FOX: cefoxitin, C: chloramphenicol, and SPT: spectinomycin.

$12.5 \%$ each. $8.33 \%$ of the isolates showed resistance to a single antimicrobial (kanamycin, tetracycline, ampicillin, and gentamycin).

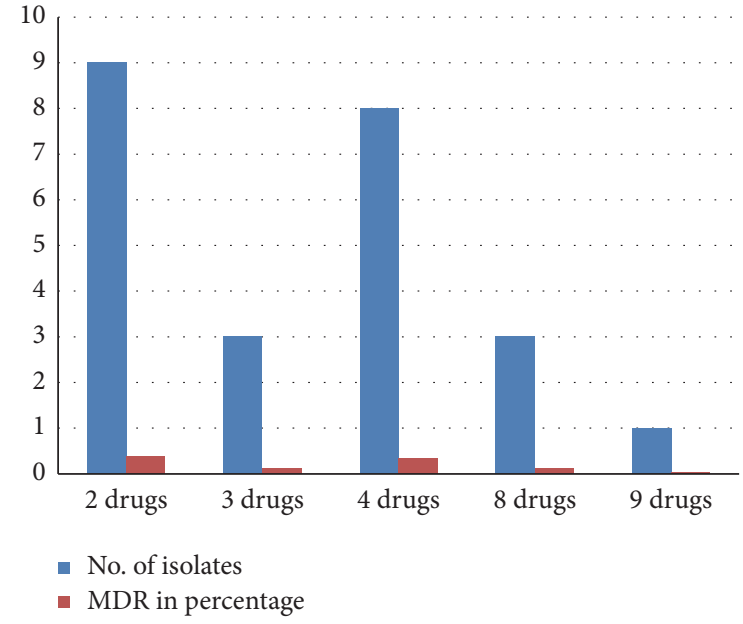

Figure 2: Multidrug resistant profiles of E. coli O157:H7 isolates of the farms.

\section{Discussion}

The occurrence of E. coli O157:H7 among poultry farms varies considerably [17]. Several studies showed $0.0 \%$ to $27.8 \%$ level of E. coli O157:H7 on poultry farms in different countries [18$20]$. In the current study, $13.4 \%(n=26)$ of E. coli O157:H7 was isolated from cloacal samples taken from poultry farms which agrees with the findings of Olatoye et al. [21] who reported 13 and 14\% level of E. coli O157:H7 from Lagos and Ibadan poultry farms, respectively. In another study, Ojo et al. [22] confirmed E. coli O157:H7 strains in the faeces of poultry sampled from different farms in Nigeria and Aibinu et al. [23] also isolated E. coli O157:H7 from chicken in Lagos and Ogun State in Nigeria who found $14.5 \%$.

Moderately comparable levels of E. coli O157:H7 were reported from different countries: $8 \%$ [24] and 8.1\% [25] in Ethiopia, 9\% [26] in India, and 6\% [27] in Turkey. However, the current finding is higher than the reports of 
Baran and Gulmez [28], Dutta et al. [29], and McCluskey et al. [30] who reported 2\%, 3.2\%, and 2.8\% level of E. coli O157:H7 in Canada, the United Kingdom, and South Africa, respectively. In addition, $4.4 \%$ occurrence was reported in Kenya [31]. These variations might be due to different sampling techniques, areas, and time and lack of strict hygienic measures among the farms and cross contamination with other principal reservoirs [24] and also due to the low isolation rate of culture methods compared to more sensitive immunological and molecular methods [32].

Chicken from Adele Poultry Farm showed E. coli O157:H7 infection four times higher than Haramaya University poultry farm and young birds had more infection than adult birds. However there was an equal chance of E. coli O157:H7 infection among different breeds of chicken. Zhao et al. [33] described young animals tend to carry E. coli O157:H7 more frequently than adults. Moreover, as young chicks are not fully immunocompetent and have also lost protection from maternal antibodies [34]. Regarding E. coli O157:H7 infection variation between the two farms might be due to security differences among the farms. However there was no statistically significant association between different breeds; this might be due to equal chance of infection among the breeds.

Antimicrobial resistance has become a global concern [35]. Indiscriminate use of antimicrobial agents in humans, veterinary, and agriculture is considered the most important factor promoting the emergence, selection, and dissemination of antimicrobial resistant microorganisms in both veterinary and human medicine [36]. There were variations in antimicrobial susceptibility of E. coli O157:H7 isolates in the present study. A complete (100\%) susceptibility was observed against ciprofloxacin and large numbers of isolates were also found to be susceptible against chloramphenicol (96.15\%), trimethoprim (92.30), gentamycin (88.46\%), spectinomycin (69.23\%), streptomycin (65.38\%), and nalidixic acid $(61.53 \%)$. Zinnah et al. [37] reported high susceptible E. coli isolates against ciprofloxacin. Similar to the current finding Hailu and Tefera [38] had reported susceptible E. coli O157:H7 isolates to chloramphenicol (100\%), spectinomycin $(62.61 \%)$, and nalidixic acid (61.76\%). Taye et al. [39] also reported most isolated strains were found susceptible to chloramphenicol and spectinomycin. Closely related chloramphenicol susceptibility to our finding was also reported by Hamisi et al. [13] and Talebiyan et al. [40] from Tanzania and Iran, respectively. The current study finding is distantly related to the finding of Moniri and Dastehgoli [41] who found 36\% of healthy broilers susceptibility to chloramphenicol and with the finding of Zakeri and Kashefi [42] who reported 51\% from cases of colibacillosis in Iran. 100\% chloramphenicol resistance isolates were reported by Islam et al. [43] from poultry in Dhaka, Bangladesh, which is in disagreement with the current study finding.

Comparable susceptible isolates (94.34\%) were reported by Talebiyan et al. [40] from chickens in Iran. Muhammad et al. [44] reported $80 \%$ susceptible E. coli isolate to gentamicin from Bangladesh which is comparable to our finding. Gentamicin was also observed in $71.7 \%$ E. coli O157:H7 isolates of poultry sample in Saudi Arabia [45]. In another work,
Miles et al. [35] had reported gentamicin susceptibility to all tested E. coli isolates. According to the report of Hassan [46] isolates were also $100 \%$ susceptible for gentamicin in layer poultry reported from Bangladesh. Susceptibility to gentamicin in the current study is distantly related to finding of Zinnah et al. [37] who reported $40 \%$ in Bangladesh. Resistance gentamicin was reported to $46.6 \%$ isolates by $\mathrm{Abd}$ El Tawab et al. [47] from broiler chickens which is higher than the current study. In contrast to the present finding low susceptible E. coli isolates were reported to nalidixic acid (29.7\%) [45], spectinomycin, trimethoprim (6\%) [48], and streptomycin (30\%) [44].

Antimicrobial resistance to clindamycin (96.15\%), erythromycin (96.15\%), ampicillin (92.30\%), cefoxitin $(84.61 \%)$, and tetracycline $(76.92 \%)$ was noted in E. coli $\mathrm{O} 157: \mathrm{H} 7$ isolates (Table 3 ). The presence and frequency of drug resistance in E. coli O157:H7 from cloacal samples agree with findings of other studies on antimicrobial resistance in $E$. coli $[38,49,50]$. High level of $E$. coli isolates resistant to ampicillin, erythromycin, and amoxicillin were also reported by former study [37]. Similar resistant isolates to tetracycline were reported by different researchers [4, 47, 51, 52]. Resistance patterns of these drugs could be due to the widespread, indiscriminate, and lengthy use of the drugs in the poultry farms $[49,53]$. Bacteria can be exposed to these antimicrobial agents in nature and used for disease treatment, for prophylaxis, or for livestock growth promotion which can lead to resistance. Plasmid mediated with a wide variety of genetic determinants also contributes to resistance in these antimicrobials [54]. This makes it more possible for a susceptible bacterium to acquire resistance factors through conjugation or transformation [35]. Furthermore, the problem is probably associated with the widespread use of these antimicrobials in humans and animals for treatment of enteric infections.

In the present study, multidrug resistance to more than two antimicrobial agents was detected in 24 (92.30\%) of the isolates. The resistance pattern most frequently observed in the isolates was resistance to erythromycin in combination with clindamycin, ampicillin, and cefoxitin 3 (12.5\%). The next most frequent resistance isolates were resistance to erythromycin, cefoxitin, clindamycin, ampicillin, amoxicillin, tetracycline, and kanamycin $2(8.33 \%)$ (Table 4$)$. Among the E. coli $\mathrm{O} 157: \mathrm{H7}$ isolates, $37.5 \%, 33.33 \%$, and $4.16 \%$ expressed resistance to two, four, and nine antimicrobials, respectively (Table 4; Figure 2), and resistance to three and eight antimicrobials occurred at a frequency of $12.5 \%$ each. $8.33 \%$ of the isolates showed resistance to a single antimicrobial (Figure 2).

Similar findings on multidrug resistance of $E$. coli strains has been reported from Ethiopia $[38,39,51]$ and other parts of the world (Khan et al. 2002; [33, 37, 43, 44, 55, 56]). Such high incidence of multidrug resistance may apparently have occurred due to indiscriminate utilization of antimicrobial agents which may ultimately replace the susceptible microorganisms $[53,57]$. Feed additives for poultry suggest encountering such resistance emergence with reduced and unsafe application of antimicrobials in animal farming and clinical purposes. The multidrug resistance observed in this study might also be mediated by genetic mobile elements 
such as plasmids, transposons, and integrons as seen in the case of other studies.

\section{Conclusion}

The study showed $13.4 \%$ of E. coli O157:H7 in cloacal swab samples in the study poultry farms. Chickens younger than six months had significantly higher level of E. coli O157:H7 compared to older chickens. A significant variation of infection was also recorded in Adele Poultry Farm compared to Haramaya University poultry farm. The study showed the presence of antimicrobial resistant isolates of E. coli O157:H7 in the studied poultry farms. E. coli O157:H7 isolates showed high level resistance to clindamycin, erythromycin, ampicillin, cefoxitin, and tetracycline which are commonly used antimicrobial agents in veterinary and human practices. The vast majority of $E$. coli $\mathrm{O} 157: \mathrm{H} 7$ isolates showed multiple drugs resistance for two to nine antimicrobials. This could have a significant public health consequence if these microorganisms are transmitted to humans through food chain. Therefore, further study is required to better understand bacterial resistance to antimicrobial agents with emphasis on surveillance of multidrug resistant $E$. coli $\mathrm{O} 157: \mathrm{H} 7$ isolates.

\section{Competing Interests}

The authors have not declared any conflict of interests.

\section{Acknowledgments}

The authors are very grateful to Haramaya University, College of Veterinary Medicine, for the material support and allowing laboratory facilities. Poultry farm workers were also acknowledged for their overall cooperation.

\section{References}

[1] J. T. Hemen, J. T. Johnson, E. E. Ambo, V. S. Ekam, M. O. Odey, and W. A. Fila, "Multi-antibiotic resistance of some gram negative bacterial isolates from poultry litters of selected farms in Benue State," International Journal of Sciences and Technology, vol. 2, no. 8, pp. 543-547, 2012.

[2] Z. Chen and X. Jiang, "Microbiological safety of chicken litter or chicken litter-based organic fertilizers: a review," Agriculture, vol. 4, no. 1, pp. 1-29, 2014.

[3] H. Karch, P. I. Tarr, and M. Bielaszewska, "Enterohaemorrhagic Escherichia coli in human medicine," International Journal of Medical Microbiology, vol. 295, no. 6-7, pp. 405-418, 2005.

[4] I. I. Romanus, O. E. Chinyere, N. E. Amobi et al., "Antimicrobial resistance of Escherichia coli isolated from animal and human clinical sample," Global Research Journal of Microbiology, vol. 2, no. 1, pp. 85-89, 2012.

[5] V. Furtula, E. G. Farrell, F. Diarrassouba, H. Rempel, J. Pritchard, and M. S. Diarra, "Veterinary pharmaceuticals and antibiotic resistance of Escherichia coli isolates in poultry litter from commercial farms and controlled feeding trials," Poultry Science, vol. 89, no. 1, pp. 180-188, 2010.

[6] S. Zhao, K. Blickenstaff, S. Bodeis-Jones, S. A. Gaines, E. Tong, and P. F. McDermott, "Comparison of the prevalences and antimicrobial resistances of Escherichia coli isolates from different retail meats in the United States, 2002 to 2008," Applied and Environmental Microbiology, vol. 78, no. 6, pp. 1701-1707, 2012.

[7] S. Moustafa and D. Mourad, "Resistance to 3rd generation cephalosporin of Escherichia coli isolated from the feces of healthy broilers chickens in Algeria," Journal of Veterinary Medicine and Animal Health, vol. 7, no. 8, pp. 290-295, 2015.

[8] E. T. Elsabet, Characterization of E. Coli Isolated from Village Chicken and Soil Samples, 2011.

[9] J. A. Odwar, G. Kikuvi, J. N. Kariuki, and S. Kariuki, "A crosssectional study on the microbiological quality and safety of raw chicken meats sold in Nairobi, Kenya," BMC Research, vol. 7, article 627, 2014.

[10] K. S. Kaye, J. J. Engemann, H. S. Fraimow, and E. Abrutyn, "Pathogens resistant to antimicrobial agents: epidemiology, molecular mechanisms, and clinical management," Infectious Disease Clinics of North America, vol. 18, no. 3, pp. 467-511, 2004.

[11] Clinical and Laboratory Standard Institute (CLSI), Performance Standards for Antimicrobial Susceptibility Testing; Twenty-Third Informational Supplement, CLSI, Wayne, Pa, USA, 2013.

[12] Central Statistics Authority (CSA), "Agricultural sample survey 2008-2009. Report on livestock and livestock characteristics, vol. II," Statistical Bulletin 446, CSA, Addis Ababa, Ethiopia, 2012.

[13] Z. Hamisi, T. Huruma, and S. Francis, "Antimicrobial resistance phenotypes of Escherichia coli isolated from tropical free range chickens," International Journal of Science and Research, vol. 3, no. 9 , p. 34, 2012.

[14] I. A. Merchant and R. A. Packer, Veterinary Bacteriology and Virology, The Iowa State University Press, Ames, lowa, USA, 7th edition, 1967.

[15] M. N. Islam, M. Sharifuzzaman, and Fakhruzzaman, "Isolation and identification of E. coli and Salmonella from poultry litter and feed," International Journal of natural and Social Science, vol. 1, pp. 1-7, 2014.

[16] P. J. Quinn, B. K. Markey, M. E. Carter, W. J. Donnelly, and F. C. Leonard, Veterinary Microbiology and Microbial Disease: Pathogenic Bacteria, Blackwell Scientific Publications, Oxford, London, 2002.

[17] A. O. Onyango, E. U. Kenya, J. J. N. Mbithi, and M. O. Ng'ayo, "Pathogenic Escherichia coli and food handlers in luxury hotels in Nairobi, Kenya," Travel Medicine and Infectious Disease, vol. 7, no. 6, pp. 359-366, 2009.

[18] P. A. Chapman, A. T. Cerdán Malo, M. Ellin, R. Ashton, and M. A. Harkin, "Escherichia coli $\mathrm{O} 157$ in cattle and sheep at slaughter, on beef and lamb carcasses and in raw beef and lamb products in South Yorkshire, UK," International Journal of Food Microbiology, vol. 64, no. 1-2, pp. 139-150, 2001.

[19] M. P. Doyle and J. L. Schoeni, "Isolation of Escherichia coli O157:H7 from retail fresh meats and poultry," Applied and Environmental Microbiology, vol. 53, no. 10, pp. 2394-2396, 1987.

[20] B. O. Abongo and M. N. B. Momba, "Prevalence and characterization of Escherichia coli O157:H7 isolates from meat and meat products sold in Amathole District, Eastern Cape Province of South Africa," Food Microbiology, vol. 26, no. 2, pp. 173-176, 2009.

[21] I. O. Olatoye, E. A. Amosun, and G. A. T. Ogundipe, "Multidrug resistant Escherichia coli O157 contamination of beef and chicken in municipal abattoirs of Southwest," Nigeria Natural Sciences, vol. 10, no. 8, pp. 125-132, 2012. 
[22] O. E. Ojo, M. A. Oyekunle, A. O. Ogunleye, and E. B. Otesile, "E. coli 0157:H7 in food animals in part of S/Western Nigeria: prevalence and invitro antimicrobial susceptibility," Tropical Veterinarian, vol. 26, pp. 23-30, 2009.

[23] I. E. Aibinu, R. F. Peters, K. O. Amisu, S. A. Adesida, M. O. Ojo, and T. Odugbemi, "Multidrug resistance in E. coli O157 strains and the public health implication," Journal of Animal Science, vol. 3, no. 3, pp. 22-33, 2007.

[24] A. Hiko, D. Asrat, and G. Zewde, "Occurrence of Escherichia coli O157:H7 in retail raw meat products in Ethiopia," The Journal of Infection in Developing Countries, vol. 2, no. 5, pp. 389-393, 2008.

[25] G. Mersha, D. Asrat, B. M. Zewde, and M. Kyule, "Occurrence of Escherichia coli O157:H7 in faeces, skin and carcasses from sheep and goats in Ethiopia," Letters in Applied Microbiology, vol. 50, no. 1, pp. 71-76, 2010.

[26] I. Luga, P. M. Akombo, J. K. P. Kwaga, V. J. Umoh, and I. Ajogi, "Seroprevalence of faecal shedding of Escherichia coli O157:H7 from exotic dairy cattle in North-Western Nigeria," Nigerian Veterinary Journal, vol. 28, no. 2, pp. 6-11, 2007.

[27] H. K. Trček, "Impact verotoxigenic E. coli O157:H7 in animals on the health of the Slovenian population," Slovenian Veterinary Research, vol. 48, pp. 83-92, 2011.

[28] F. Baran and M. Gulmez, "The occurrence of Escherichia coli O157:H7 in the ground beef and chicken drumsticks," Internet Journal of Food Safety, vol. 2, pp. 13-15, 2010.

[29] S. Dutta, A. Deb, U. K. Chattopadhyay, and T. Tsukamoto, "Isolation of shiga toxin-producing Escherichia coli including O157:H7 strains from dairy cattle and beef samples marketed in Calcutta, India," Journal of Medical Microbiology, vol. 49, no. 8, pp. 765-767, 2000.

[30] B. J. McCluskey, D. H. Rice, D. D. Hancock et al., "Prevalence of Escherichia coli $\mathrm{O} 157$ and other Shiga-toxin-producing E. coli in lambs at slaughter," Journal of Veterinary Diagnostic Investigation, vol. 11, no. 6, pp. 563-565, 1999.

[31] P. A. Chapman, C. A. Siddons, A. T. Cerdan Malo, and M. A. Harkin, "A one year study of Escherichia coli O157 in raw beef and lamb products," Epidemiology and Infection, vol. 124, no. 2, pp. 207-213, 2000.

[32] A. Govaris, A. S. Angelidis, K. Katsoulis, and S. Pournaras, "Occurrence, virulence genes and antimicrobial resistance of escherichia coli o157 in bovine, caprine, ovine and porcine carcasses in greece," Journal of Food Safety, vol. 31, no. 2, pp. 242-249, 2011.

[33] S. Zhao, J. J. Maurer, S. Hubert et al., "Antimicrobial susceptibility and molecular characterization of avian pathogenic Escherichia coli isolates," Veterinary Microbiology, vol. 107, no. 3-4, pp. 215-224, 2005.

[34] J. Pitcovski, D. E. Heller, A. Cahaner, and B. A. Peleg, "Selection for early responsiveness of chicks to Escherichia coli and Newcastle disease virus," Poultry Science, vol. 66, no. 8, pp. 1276$1282,1987$.

[35] T. D. Miles, W. McLaughlin, and P. D. Brown, "Antimicrobial resistance of Escherichia coli isolates from broiler chickens and humans," BMC Veterinary Research, vol. 2, article no. 7, 2006.

[36] G. S. Simonsen, J. W. Tapsall, B. Allegranzi, E. A. Talbot, and S. Lazzari, "The antimicrobial resistance containment and surveillance approach - a public health tool," Bulletin of the World Health Organization, vol. 82, no. 12, pp. 928-934, 2004.

[37] M. H. Zinnah, M. T. Haque, M. T. Islam et al., "Drug sensitivity pattern of Escherichia coli isolated from samples of different biological and environmental sources," Bangladesh Journal of Veterinary Medicine, vol. 6, no. 1, pp. 13-18, 2008.

[38] D. Hailu and G. Tefera, "Isolation and characterization of multidrug resistant Escherichia coli isolates from contagion syndrome poultry farm," International Journal of Current Trends in Pharmacobiology and Medical Sciences, vol. 1, no. 2, pp. 19-26, 2016.

[39] M. Taye, T. Berhanu, Y. Berhanu, F. Tamiru, and D. Terefe, "Study on carcass contaminating Escherichia coli in apparently healthy slaughtered cattle in Haramaya University slaughter house with special emphasis on Escherichia coli o157:H7, Ethiopia," Journal of Veterinary Science and Technology, vol. 4, no. 1, article no. 132, 2013.

[40] M. K. Talebiyan, K. Faham, and R. F. Mohammad, "Multiple antimicrobial resistance of Escherichia coli isolated from chickens in Iran," Veterinary Medicine International, vol. 2014, Article ID 491418, 4 pages, 2014.

[41] R. Moniri and K. Dastehgoli, "Fluoroquinolone-resistant Escherichia coli isolated from healthy broilers with previous exposure to fluoroquinolones: is there a link?" Microbial Ecology in Health and Disease, vol. 17, no. 2, pp. 69-74, 2005.

[42] A. Zakeri and P. Kashefi, "Isolation and drug resistance patterns of Escherichia coli from cases of colibacillosis in Tabriz," Journal of Animal and Veterinary Advances, vol. 11, no. 19, pp.3550-3556, 2012.

[43] M. J. Islam, S. Sultana, K. K. Das, N. Sharmin, and M. N. Hasan, "Isolation of plasmid-mediated multidrug resistant Escherichia coli from poultry," International Journal of Sustainable Crop Production, vol. 3, no. 5, pp. 46-50, 2008.

[44] A. Muhammad, S. Akond, S. M. Alam, R. Hassan, and S. Momena, "Antibiotic resistance of Escherichia coli isolated from poultry and poultry environment of Bangladesh," Internet Journal of Food Safety, vol. 11, pp. 19-23, 2009.

[45] A. D. Altalhi, Y. A. Gherbawy, and S. A. Hassan, "Antibiotic resistance in Escherichia coli isolated from retail raw chicken meat in Taif, Saudi Arabia," Foodborne Pathogens and Disease, vol. 7, no. 3, pp. 281-285, 2010.

[46] M. M. Hassan, "Antimicrobial resistance pattern against E. coli and Salmonellain layer poultry," Research Journal for Veterinary Practitioners, vol. 2, no. 2, pp. 30-35, 2014.

[47] A. A. Abd El Tawab, A. M. Ammar, S. A. Nasef, and R. M. Reda, "Prevalence of E. coli in diseased chickens with its antibiogram pattern," Benha Veterinary Medical Journal, vol. 28, no. 2, pp. 224-230, 2015.

[48] J. Isendahl, A. Turlej-Rogacka, C. Manjuba, A. Rodrigues, C. G. Giske, and P. Nauclér, "Fecal carriage of ESBL-producing E. coli and K. pneumoniae in children in Guinea-Bissau: a HospitalBased Cross-Sectional Study," PLoS ONE, vol. 7, no. 12, Article ID e51981, 2012.

[49] A. E. van den Bogaard, N. London, C. Driessen, and E. E. Stobberingh, "Antibiotic resistance of faecal Escherichia coli in poultry, poultry farmers and poultry slaughterers," Journal of Antimicrobial Chemotherapy, vol. 47, no. 6, pp. 763-771, 2001.

[50] R. S. Sayah, J. B. Kaneene, Y. Johnson, and R. Miller, "Patterns of antimicrobial resistance observed in Escherichia coli isolates obtained from domestic-and wild-animal fecal samples, human septage, and surface water," Applied and Environmental Microbiology, vol. 71, no. 3, pp. 1394-1404, 2005.

[51] T. Zeryehun and B. Bedada, "Antimicrobial resistant pattern of fecal E. coli in selected broiler farms of eastern Harare zone, Ethiopia," International Journal of Applied Biology and Pharmaceutical Technology, vol. 4, no. 4, pp. 298-304, 2013. 
[52] O. O. Adelowo, O. E. Fagade, and Y. Agersø, "Antibiotic resistance and resistance genes in Escherichia coli from poultry farms, southwest Nigeria," Journal of Infection in Developing Countries, vol. 8, no. 9, pp. 1103-1112, 2014.

[53] A. E. Van Den Bogaard and E. E. Stobberingh, "Antibiotic usage in animals. Impact on bacterial resistance and public health," Drugs, vol. 58, no. 4, pp. 589-607, 1999.

[54] J. F. Prescott, J. D. Baggot, and R. D. Walker, Antimicrobial Therapy in Veterinary Medicine, Iowa State Press, Ames, Iowa, USA, 3rd edition, 2000.

[55] B. Guerra, E. Junker, A. Schroeter, B. Malorny, S. Lehmann, and R. Helmuth, "Phenotypic and genotypic characterization of antimicrobial resistance in German Escherichia coli isolates from cattle, swine and poultry," Journal of Antimicrobial Chemotherapy, vol. 52, no. 3, pp. 489-492, 2003.

[56] E. A. Amosun and I. O. Olatoye, "Molecular characterization and antibiotic resistance profile of Escherichia coli from food producing animals from Southwest Nigeria," American Journal of Science, vol. 12, no. 8, pp. 51-56, 2016.

[57] J. M. Miranda, B. I. Vázquez, C. A. Fente, J. Barros-Velázquez, A. Cepeda, and C. M. Franco, "Evolution of resistance in poultry intestinal Escherichia coli during three commonly used antimicrobial therapeutic treatments in poultry," Poultry Science, vol. 87, no. 8, pp. 1643-1648, 2008. 

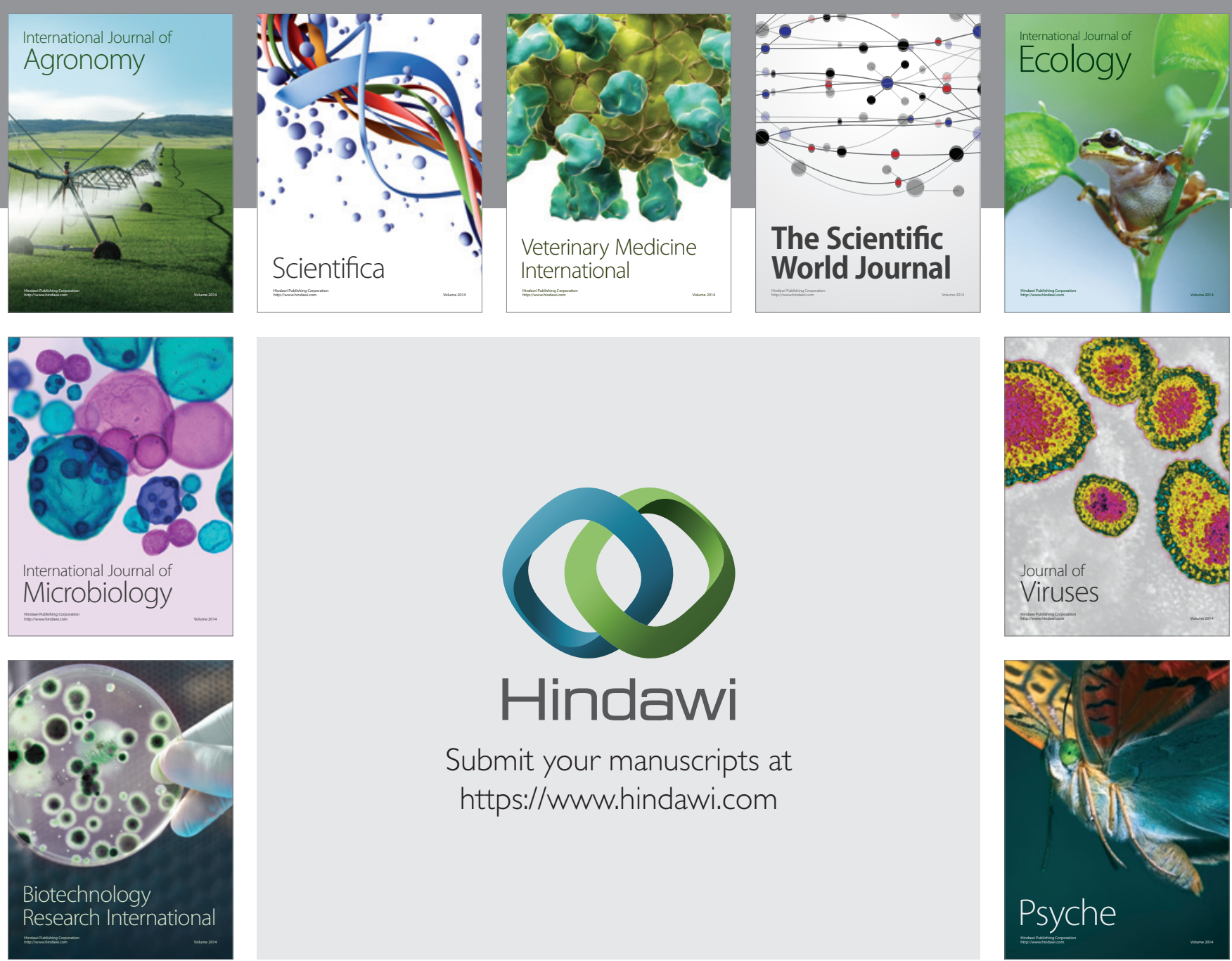

\section{Hindawi}

Submit your manuscripts at

https://www.hindawi.com
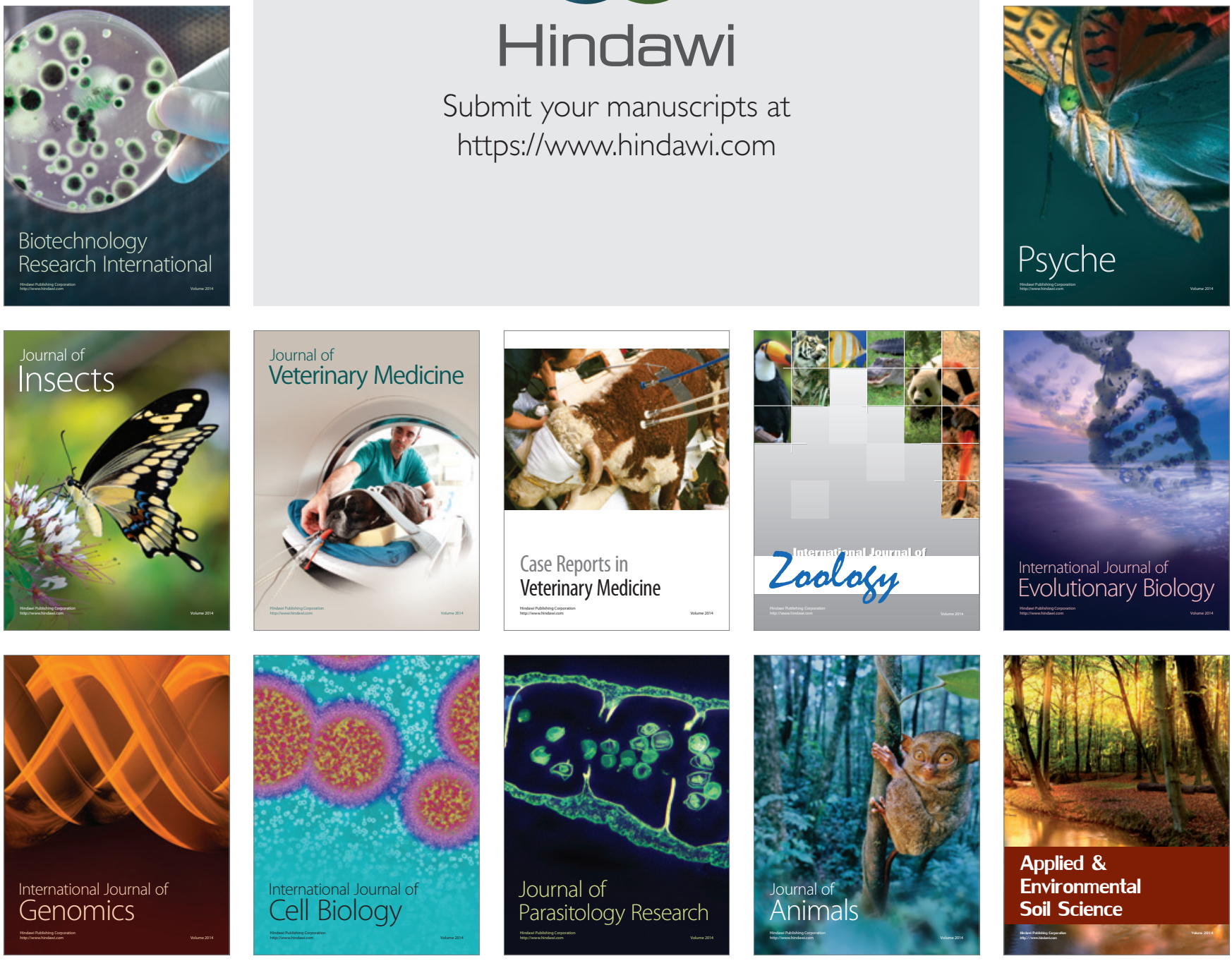